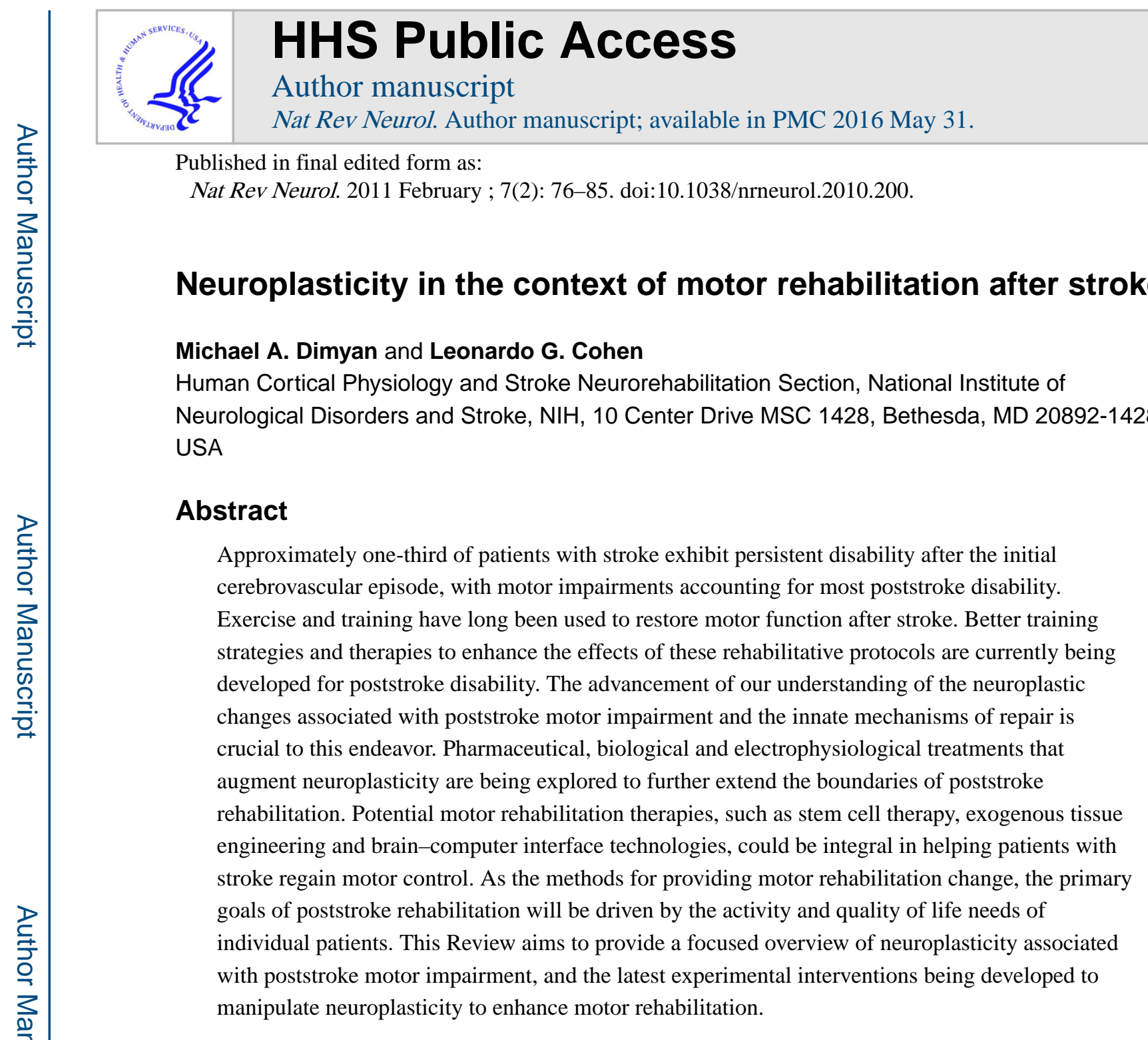

\title{
Introduction
}

Stroke is one of the most prevalent neurological conditions worldwide, especially among the elderly. ${ }^{1}$ This cerebrovascular disorder can cause a variety of symptoms and, in severe cases, may lead to death. Motor impairment is one of the main disabilities associated with stroke, and where an environment has not been modified to accommodate a patient's functional limitations - for example, an absence of assistive devices to aid activities of daily livingtheir physical disability can substantially affect their quality of life.

The ability of training and physical activity to restore motor function after neural injury has long been appreciated. ${ }^{2}$ This observation has led to the establishment of rehabilitation and,

Correspondence to: L. G. Cohen, ; Email: cohenl@ ninds.nih.gov

Competing interests

The authors declare no competing interests.

Author contributions

M. A. Dimyan and L. G. Cohen researched the data and wrote the article, and provided substantial contributions to discussions of the content, reviewing and editing of the manuscript. 
notably, neurorehabilitation as clinical disciplines. Innate physiological and anatomical plasticity are important processes that underlie substantial gains in motor function after stroke, ${ }^{2,3}$ and the combination of task-specific training and general aerobic exercise is still the gold-standard treatment for poststroke rehabilitation. Nevertheless, even with intensive task-specific training and physical activity, $15-30 \%$ of patients with stroke are permanently disabled. $^{4}$ As a result, research aiming to develop novel therapies that enhance neuroplasticity is currently being conducted to allow rehabilitation of these patients.

This area of research can be divided into three different arms, all of which are at relatively early stages of development. The first research arm relates to the study of the molecular and cellular mechanisms of normal movement and the pathophysiological processes involved in poststroke paresis. An in-depth understanding of the pathophysiological mechanisms of stroke-related paresis should lead to improvements in prognostic indicators of functional recovery, and more effective interventions to improve relearning of lost motor function than are currently available. ${ }^{57}$ The second research arm is concerned with the development of pharmacological, biological and electrophysiological techniques that can augment traininginduced plasticity. ${ }^{8}$ Both of these research arms aim to understand and enhance innate plasticity in the adult CNS, so that this neural process can be harnessed to aid poststroke rehabilitation. ${ }^{2,9}$ Nevertheless, the degree of neuroplasticity that can occur in the adult brain is unknown, and the extensive neural reorganization that is observed in children after hemispherectomy ${ }^{10},{ }^{11}$ might not be inherently possible in adults. ${ }^{12}{ }^{13}$ Thus, the third research arm aims to utilize advances in biomedical and tissue engineering to promote functional recovery within the brain. Of note, attempts have been made to promote neural repair or replacement through use of innate or exogenous stem cells. ${ }^{14}, 15$ Another prominent research avenue involves developing neuroprosthestics and brain-computer-interface technologies to bypass injury via adaptive remote neuroplasticity, whereby part of the nervous system not originally dedicated to a particular task can be harnessed to provide the neural substrate that interacts with the neuroprosthesis or brain-computer device. ${ }^{16}$

Socioeconomic, political and environmental factors need to be accounted for to fully address the complex issues associated with poststroke disability; ${ }^{17}$ however, this review only focuses on the biological aspects of motor impairment after stroke, and the therapies being developed to restore motor function. unlike other reviews that have critically assessed the efficacy of poststroke treatments ${ }^{18} 20$ or have focused on the contributions of neuroprotection and reperfusion to functional recovery, ${ }^{21},{ }^{22}$ this article examines research aiming to enhance neuroplasticity after stroke. By assessment of the biological aspects of voluntary movement and neural plasticity that are being translated into the field of poststroke motor rehabilitation, we will highlight the most consistent and significant findings in the three arms of neurorehabilitation research outlined above. In this article, special emphasis is given to studies of the pathophysiology of poststroke paresis and the development of electrophysiological interventions that, when combined with customary training-based protocols, could aid motor rehabilitation in patients with stroke. 


\section{Current standard of care}

Poststroke rehabilitation requires managing the disability and the chronic diseases that cause or accompany the stroke. International guidelines have been developed on the basis of available data to promote best clinical practice in poststroke rehabilitation. ${ }^{23}{ }^{25}$ For the rehabilitation of motor functions, dedicated rehabilitative strategies involving both physical and occupational therapy, among other treatments, are recommended. These treatments should preferably be undertaken in a specialized rehabilitation unit. The guidelines also emphasize the use of general aerobic exercise to regain physical endurance and intense taskdirected training to attain specific functional gains. Few comprehensive systematic reviews have evaluated the effectiveness of the various training techniques; ${ }^{26}$ however, some of these therapies are associated with marked improvements in motor function. For example, constraint-induced movement therapy - a regimen involving comfortable restraint of the nonparetic limb in conjunction with 'forced'use of the paretic limb in activities of daily living, and in intensive functional training - has been shown to be associated with an immediate decrease in disability rating scores in several meta-analyses. ${ }^{27} 29$ By contrast, while individual trials have shown that body weight-supported treadmill training is associated with gains in motor function, ${ }^{30}$ a systematic review of the literature relating to this approach came to a different conclusion. ${ }^{31}$ Other techniques such as motor imagery, ${ }^{32}, 33$ bilateral arm training ${ }^{34}$ and robot-assisted therapy ${ }^{35,}{ }^{36}$ might also improve motor function in patients with stroke, but the limited number of studies that have investigated these techniques precludes the formulation of meaningful guidelines for their use. ${ }^{19},{ }^{37} 393$ previous assumption that expensive and complex rehabilitative methods could not be tested in randomized clinical trials has been proved incorrect by the implementation of several large, well-designed clinical studies, and systematic reviews examining these trials have led to improvements in evidence-based approaches of poststroke rehabilitation. ${ }^{36,40-42}$

\section{Poststroke physiology}

Preclinical studies provide a means of exploring the cellular and molecular pathophysiological processes associated with hemiparesis and/or stroke and the physiological processes underlying spontaneous recovery after experimental brain injury. Studies in rodent models of stroke indicate that synaptogenesis increases substantially after experimental lesioning, and that dendrite number and shape are altered following infarction. Furthermore, both synaptogenesis and dendrite remodeling are associated with increases in neurological activity in the 'motor map' in the ipsilesional ${ }^{43}$ and contralesional cerebral cortices. Axonal reorganization has also been demonstrated in rodent models of stroke, indicating that this process might be critical for spontaneous recovery after infarction. ${ }^{45}, 46$ Data from animal models also support the use of task-specific training and generalized aerobic exercise in poststroke rehabilitation, and show that these measures can activate molecular pathways - such as the upregulation of brain-derived neurotrophic factor-that are important for neurogenesis as well as learning and memory. ${ }^{47}$ Furthermore, task-specific training in animal models of brain injury has been shown to induce changes in neural architecture, such as neural sprouting, synaptogenesis and dendritic branching. ${ }^{48} 52$ Anatomical and physiological changes are also known to occur with other types of motor training in rodents; for example, endurance training increases metabolic demand and leads to 
angiogenesis, while skill-specific training induces synaptogenesis and synaptic potentiation. 53

In humans, structural ${ }^{54,55}$ and metabolic brain imaging ${ }^{56} 59$ and electrophysiological recording of the primary motor cortices ${ }^{60} 63$ have been used to document reorganization of neural activity after stroke, with both ipsilesional and contralesional primary motor cortices and the dorsal premotor cortex having been identified as areas that can undergo substantial poststroke neuroplasticity. evidence of this neural activity has led researchers to investigate ways of predicting potential poststroke recovery. As a result of these investigations, among patients with stroke, those with low contralesional primary motor cortex activity and evidence of ipsilesional motor cortex-evoked potentials to transcranial magnetic stimulation maybe considered more likely to recover from stroke-associated motor deficits than those who do not exhibit such phenomena. $58,59,64,65$

Evidence of neural reorganization after stroke might also lead to the development of novel interventions that promote poststroke rehabilitation. ${ }^{66}$ Studies using neuroimaging and neurophysiological techniques to identify changes in both metabolic activity ${ }^{67}$ and anatomical connections ${ }^{68}$ in the brain to investigate poststroke motor network dynamics indicate that non-primary motor areas might contribute significantly to movement of the paretic limb after stroke. Transient disruption of activity in the contralesional premotor cortex through use of transcranial magnetic stimulation (TMS) has been shown to briefly alter hand movements in patients with stroke. ${ }^{69}$ A limitation of neuroimaging techniques such as functional MrI or PeT is that although they can identify abnormal brain network activity after stroke, they are unable to determine whether such activity is inhibitory or excitatory in nature. ${ }^{70}$ By contrast, intracellular and extracellular electrophysiological recordings can identify poststroke changes in neural activity and determine whether these changes are inhibitory or excitatory. These approaches are limited, however, in relation to the number of networks that can be examined at any one time. ${ }^{7,67} 69,71$

Through use of electrophysiological and neuroanatomical measures of neural activity in combination, thereby circumventing each technique's limitations, Stinear and colleagues 54 were able to predict whether patients with stroke were likely to regain any meaningful motor function. Patients with measurable motor-evoked potentials (MePs) following TMS were deemed to have the best prognosis, regaining more motor functionality than patients who did not exhibit such responses to TMS. Nevertheless, patients who lacked measurable MePs following TMS could be subdivided into groups through measurement of white matter corticospinal integrity. using diffusion tensor imaging, the researchers measured functional anisotropy of the ipsilesional and contralesional white matter tracts in the brain. Patients with functional anisotropy asymmetry $\searrow 0.25$-indicating significantly lower white matter tract integrity on the ipsilesional side than on the contralesional side-were unlikely to show any meaningful recovery. In an extension to these findings, electrophysiological evidence has indicated that corticospinal integrity might be the most important factor that influences poststroke recovery during the acute stage after stroke, whereas changes in local motor cortex circuitry might have the most influence on recovery potential 3 months after stroke. ${ }^{62}$ 
Taken together, the research discussed above and other studies of compensatory or detrimental physiological processes associated with stroke have identified targets for novel interventional therapies to exploit; these therapies will be discussed in the next section. Currently, these novel treatments are not customarily used in the clinic; however, the establishment of standards and guidelines for the study of poststroke functional recovery and its physiological correlates and markers, ${ }^{72},{ }^{73}$ along with closer collaboration between basic and clinical scientists, ${ }^{74}$ will probably promote the development of such therapies and lead to advances in neural repair and rehabilitation. As with any potential marker of poststroke recovery, it will be important to determine their relationship not only to quantitative functional outcomes, but also to measures of activities of daily living, participation and quality of life.

\section{Strategies to promote plasticity}

\section{Pharmacological interventions}

Pharmacological interventions that act on neurotransmitter systems might promote neural plasticity and could potentially enhance the effectiveness of poststroke motor therapies. Preclinical studies involving decerebrated cats or rodent models of brain injury ${ }^{75,76}$ have revealed that amphetamine treatment - through increased presynaptic release of dopamine and norepinephrine, and inhibition of neurotransmitter reuptake-may have therapeutic effects following brain injury. Basic forms of motor training in humans can be enhanced by amphetamines, ${ }^{77}, 78$ and these findings are consistent with the results of several small clinical trials of these drugs, which have shown that amphetamine treatment can decrease the level of motor impairment on tests such as the Fugl-Meyer score in patients with cerebral infarction. ${ }^{79}$ enthusiasm for amphetamine treatment has waned, however, since larger trials of this therapy yielded mixed results: while four trials showed that amphetamine treatment was associated with some rehabilitative benefit in patients with stroke, four other trials indicated that this treatment provided no benefit in this patient group. ${ }^{80}$ Furthermore, a meta-analysis determined that, given the detrimental cardiovascular effects associated with amphetamines, ${ }^{81}$ insufficient data existed to support the use of amphetamine therapy in the treatment of stroke. ${ }^{82}$ Some investigators argue that the inconsistent results associated with this treatment might reflect the use of inappropriate animal models in preclinical studies, heterogeneity in brain lesions, use of inappropriate doses of amphetamines, and/or administration of such drugs at suboptimal time points during clinical studies. ${ }^{80}, 83$ Future clinical trials will benefit from a re-examination of these issues and use of morehomogeneous strategies than were employed in previous trials (Figure 1).

Complex behavioral factors such as motivation, which might not be easily translated from animal models to human patients, might account for inconsistencies observed between clinical trial data and predictions arising from the results of preclinical studies. This hypothesis might explain why inconsistent results have been associated with the use of levodopa in patients with stroke. ${ }^{84},{ }^{85}$ Drugs that enhance the activity of the cholinergic system, which is known to modulate neural activity throughout the cortex, are also being tested for their ability to enhance poststroke motor rehabilitation. In addition to their proven ability to enhance memory and executive function in patients with Alzheimer disease, these 
compounds have also been associated with improvements in sensorimotor function and overall activities of daily living in case studies and small trials involving patients with stroke. $^{86 \_89}$ whether such enhancement of motor rehabilitation is a direct consequence of improvements in motor learning or simply a reflection of the drugs' cognitive effects is not fully understood. Nevertheless, further research into the use of pharmacotherapy in poststroke motor rehabilitation, and its potential impact on disability, is required before pharmacological treatment is employed in clinical care. 90

Since the discovery of nerve growth factors ${ }^{91}$ and the demonstration that neurogenesis could occur in the adult brain, ${ }^{92}$ researchers have postulated that exogenous treatments that stimulate neurogenesis could improve recovery after stroke. ${ }^{93}{ }^{97}$ Preclinical studies have examined the ability of various growth factors, hormones and cytokines-including granulocyte colony-stimulating factor, ${ }^{98}{ }^{100}$ erythropoietin ${ }^{101}{ }^{103}$ and brain-derived neurotrophic factor ${ }^{104 \_106}$ — to enhance motor rehabilitation after experimental ischemia, and these three proteins have all been found to improve both specific motor scores and more general behavioral scores in rodent models of stroke. Translation of these findings into clinical trials is just beginning, but although these three proteins could be promising future poststroke therapies, they are all associated with substantial safety concerns. For instance, while erythropoietin exhibited neuroprotective effects in animal models, the largest clinical trial of erythropoietin therapy conducted to date actually showed that, compared with placebo, this treatment was associated with an increased risk of mortality in patients with acute ischemic stroke. ${ }^{107}$ The observed increase in mortality risk associated with erythropoietin might have reflected an interaction between this agent and other stroke treatments administered during the trial. Indeed, the trial's investigators noted that a high number of patients involved in the study also received recombinant tissue plasminogen activator (rtPA), and rtPA may have caused hemorrhages in immature vasculature that developed as a result of erythropoietin therapy. erythropoietin might have also interacted detrimentally with common stroke-related comorbidities such as hypertension and diabetes, and such interactions may not have been anticipated in preclinical experiments. ${ }^{107,108}$

\section{Nervous system stimulation}

Therapies that directly stimulate the PNS or CNS may enhance neuroplasticity during poststroke rehabilitation, and might help patients with stroke overcome their motor impairments. For example, devices that provide electrical stimulation to peripheral nerves and muscles might assist stroke patients with hemiparesis move their affected limbs. Furthermore, PNS stimulation can influence the CNS via afferent pathways, and some PNS stimulation protocols have been designed specifically to induce cortical plasticity. For example, repetitive peripheral nerve stimulation has been shown to improve both strength in paretic limbs and learning of a sequential finger-tapping sequence in patients with stroke (Figure 1). ${ }^{109 \_117}$

Stimulation of the CNS, specifically the primary motor cortex (M1), might directly enhance motor rehabilitation after stroke. TMS and direct current stimulation (Figure 1) offer noninvasive approaches of stimulating the cortical surface of the brain, while epidural electrodes can be surgically implanted to stimulate the motor cortex directly. ${ }^{8}{ }^{118}$ Since 
'normal' limb movement is accompanied by a transient increase in excitability in the corticospinal tract, numerous research groups have investigated the use of electrical stimulation-either applied transcranially ${ }^{119}{ }^{130}$ or through implanted epidural electrodes ${ }^{131}{ }^{133}$ _ to exogenously increase the excitability of the stroke-affected ipsilesional M1 in order to improve function. Most studies of ipsilesional M1 stimulation have demonstrated an improvement in at least one motor ability, such as an active range of motion, or have demonstrated improved performance on specific functional rehabilitation tests. Interventions that stimulate the M1 are still at the experimental stage and, consequently, have not been subjected to large, well-controlled clinical trials that test their effects on patient activity and/or participation. Nevertheless, a double-blind, controlled, multicenter clinical trial that aims to investigate the efficacy of transcranial direct current stimulation combined with physical therapy to enhance rehabilitation after stroke is under way. ${ }^{134}$ The exact mechanisms of action of these techniques are under investigation, ${ }^{135}$ but improvements in motor function that are associated with stimulation of the CNS might occur as a direct result of changes in synaptic activity and gene expression, and increases in neurotransmitter, receptor and neurotrophin levels. ${ }^{136 \_139}$ Furthermore, the efficacy of these techniques seems to be highly dependent on the intensity, duration and frequency of the electrical stimulation, as well as on the area of the brain being stimulated. ${ }^{139}$

Metabolic brain imaging often reveals abnormally high levels of activity in the contralateral motor cortex of patients with stroke. ${ }^{140 \_143}$ The functional role of this activity is unknown; however, electrophysiological data indicate that interhemispheric inhibition of the ipsilesional M1 by the contralesional M1 is abnormally persistent during movement of the paretic hand. ${ }^{63},{ }^{144}$ Together, these data support the hypothesis that interhemispheric competition $^{145}$ might be a factor that influences motor rehabilitation after stroke. Thus, the contralesional M1 has become a major target for interventional therapy for poststroke rehabilitation (Figure 1). Several studies have demonstrated small but significant improvements in both simple and more complex tests of hand function in patients with subacute or chronic stroke who have undergone stimulation to decrease excitability in the contralesional M1, ${ }^{122},{ }^{128},{ }^{146} 152$ although a recent trial has shown contradictory results. ${ }^{153}$

The combination of PNS and CNS stimulation to promote neuroplasticity has been investigated in preclinical studies and in a small trial involving patients with stroke, ${ }^{154 \_158}$ and promising results for this approach have been reported. In one study of patients with stroke, repetitive low-intensity peripheral stimulation of the paretic limb with subsequent transcranial direct current stimulation of the affected primary motor cortex resulted in improved procedural learning of a finger-tapping sequence. ${ }^{154}$ Furthermore, paired associative stimulation, whereby peripheral stimulation and central stimulation are timed to coincide in such a way as to induce spiketiming-dependent plasticity, has been used to promote motor recovery in a rodent model of stroke, ${ }^{155}$ but this technique has only demonstrated electrophysiological effects in patients with stroke to date. ${ }^{156,157}$

Taken together, most early clinical studies of nervous system stimulation (reviewed above) have demonstrated some positive effects on poststroke motor rehabilitation. Nevertheless, the overall effect sizes observed in these studies have not been significantly greater than those demonstrated with behavioral therapy alone. ${ }^{118}$ To address the issue of treatment 
efficacy for nervous system stimulation, new trials are being designed that extend the duration of treatment, combine complementary methods of stimulation, and identify patients most likely to benefit from each intervention. Treatment effect sizes may improve when patients with similar strokerelated impairments are enrolled in large studies and when the most effective stimulation protocol and clinically relevant functional outcome measures are identified. ${ }^{118}$ Nevertheless, our understanding of the dynamics of inhibition and excitation within the motor system, upon which stimulation studies are based, is still incomplete. Thus, a better understanding of the connectivity and interactions within the motor system might lead to more-efficacious stimulation protocols. ${ }^{7,159,160}$ Such therapies will all need to be assessed with regard to their outcomes on patient activity and quality of life before becoming part of clinical practice.

\section{Novel treatments}

\section{Stem cells}

Above, we have reviewed the areas of research that aim to enhance innate repair mechanisms within the CNS after stroke, but there might be a limit to how much endogenous regeneration can be augmented and supported. These issues might be circumvented through replacement of damaged neural tissue by use of artificial or exogenous materials to improve neural regrowth, or bypassing stroke-related impairment by developing prosthetics that are directly connected to the CNS (for example, an orthosis that moves a paralyzed limb by taking instructions directly from the brain). Preclinical success with neural stem cell therapy, despite limited understanding of the mechanisms of action, dosing and possible adverse effects, ${ }^{161}$ has led to the first clinical trial of such therapy for poststroke hemiparesis, which is being conducted in the $\mathrm{uK}^{162}$

In preclinical studies, both human-derived and rodentderived stem cells were transplanted into rodents with experimentally induced stroke, where they migrated to the location of the lesion and developed into electrophysiologically and anatomically mature neurons. (Figure 1). One area of preclinical research attempting to improve the success of this treatment approach is focusing on how exogenous scaffolding or modulation of the local environment might improve the proliferation and growth of stem cells. ${ }^{15,163,164}$ By providing an artificial extracellular environment that promotes appropriate cell growth, nanotechnology could have a role in improving and modifying stem cell therapy (Figure 1). ${ }^{165}$

\section{Neuroprosthetics}

Prosthetics and orthotics have generally been designed to provide support for a weak limb, and only indirect effects on function have usually been associated with these kinds of devices. However, if orthotics could be developed that enable patients with stroke to achieve their intended motor goals, such as walking unaided, these devices could serve a more functional purpose (Figure 1). research into both invasive and noninvasive brain-computer and nerve-computer interfaces has shown that patients with stroke can control exogenous systems through training. ${ }^{166 \_168}$ In one study, magnetoencephalography was used to record the sensorimotor $\mu$ rhythm over the affected M1 region of patients with chronic hemiparesis. These patients successfully learned to use motor imagery to control the mu rhythm and, 
through the brain-computer interface, to control an orthotic device that opened and closed their paralyzed hand (Figure 2). ${ }^{167}$ In addition, a single case report has shown that an eeG brain-computer interface enabled a patient with chronic stroke to control functional electrical stimulation of her paretic limb, leading to voluntary finger extension. ${ }^{169}$ Interestingly, the neuroprosthetic methods highlighted above are being explored not only as a means to bypass injury, but also as a means by which to encourage training and practice; for instance, robotic devices have been used as training tools to promote neuroplasticity (Figure 1). ${ }^{170}$

\section{Future therapies}

Motor rehabilitation after stroke will no doubt benefit from continued advances in basic systems neuroscience. For example, the development of optogenetics ${ }^{171},{ }^{172}$ and noninvasive ultrasound $^{173}$ could offer new ways of studying and guiding neural plasticity with increasing accuracy. Furthermore, understanding how genetic polymorphisms affect the therapeutic potential of various training and stimulation protocols ${ }^{135,174,175}$ could allow molecular and electrophysiological interventions to be combined synergistically to improve corticospinal tract repair after stroke. These nascent areas of rehabilitative research, however, all require significant investment to bring them into clinical practice.

\section{Defining rehabilitation goals}

As research into poststroke neuroplasticity and motor rehabilitation evolves, assessment of the motor outcomes that benefit patient activity and participation, ${ }^{176}$ and the patients own rehabilitative goals, will be important. ${ }^{177}$ we should anticipate that interventions that restore body functions and those that increase participation might not be viewed equally by patients, and that patient satisfaction may itself depend on a balance between restoring body functions and increasing participation. In the case of interventions that are associated with marked success in clinical studies, patients may not always feel that the benefits of such treatments are worth the sacrifices and effort required to see such rewards. ${ }^{178}$ Thus, future clinical research into poststroke rehabilitation should employ assessments of quality of life and patient satisfaction. ${ }^{179}, 180$

Defining the specific purpose of rehabilitative treatments, both before such therapies are tested in trials and once they are used clinically, is important, since the goals of one particular intervention may actually conflict with the goals of a different intervention. For example, training protocols that focus on relearning how to perform a particular motor task in the same manner to how it was carried out before the stroke might be substantially different from treatments that aim to teach the patient how to execute a task through a set of adaptive strategies. ${ }^{181}$ Furthermore, the choice of one strategy over another approach might determine which aspect of neuroplasticity is enhanced, and could limit the efficacy of other forms of plasticity. we will probably find that patient preferences as well as genetic and social factors will affect each patient's responses to rehabilitative therapies; thus, customization of poststroke therapies will probably be required in the future. ${ }^{182}{ }^{183}$ 


\section{Conclusions}

Motor rehabilitation after stroke continues to be an area in need of substantial financial and scientific investment. Our understanding of the mechanisms underlying strokeinduced paralysis is increasing and, with this knowledge, our ability to modulate the neural structures affected by stroke and to stimulate neuroplasticity is improving. Advances in technology are aiding the development of therapies that can augment innate repair mechanisms or, even, bypass such processes, thereby providing alternate methods to carry out tasks of daily living. As the number of methods for modulating stroke-related physiological processes increase, so must the emphasis on measuring both functional outcomes and quality of life in patients. Poststroke neurorehabilitation is evolving into a field dominated by multidisciplinary interactions and collaborations, as therapists, molecular biologists, engineers, physiologists, physicians and patients work together towards the goal of improving the quality of life of patients with stroke.

\section{Acknowledgments}

This work was supported by the Intramural Research Program of the National Institute of Neurological Disorders and Stroke, NIH. The original illustrations used for Figure 1 were by G. Qushair of SciLingua.

\section{References}

1. Sousa RM, et al. Contribution of chronic diseases to disability in elderly people in countries with low and middle incomes: a 10/66 Dementia Research Group population-based survey. Lancet. 2009; 374:1821-1830. [PubMed: 19944863]

2. Nudo RJ, Wise BM, SiFuentes F, Milliken GW. Neural substrates for the effects of rehabilitative training on motor recovery after ischemic infarct. Science. 1996; 272:1791-1794. [PubMed: 8650578]

3. Taub E, Uswatte G, Elbert T. New treatments in neurorehabilitation founded on basic research. Nat. Rev. Neurosci. 2002; 3:228-236. [PubMed: 11994754]

4. Lloyd-Jones D, et al. Heart Disease and Stroke Statistics-2009 update: a report from the American Heart Association Statistics Committee and Stroke Statistics Subcommittee. Circulation. 2008; 119:480-486. [PubMed: 19171871]

5. Krakauer JW. Motor learning: its relevance to stroke recovery and neurorehabilitation. Curr. Opin. Neurol. 2006; 19:84-90. [PubMed: 16415682]

6. Seitz RJ. How imaging will guide rehabilitation. Curr. Opin. Neurol. 2010; 23:79-86. [PubMed: 19926990]

7. Dimyan MA, Cohen LG. Contribution of transcranial magnetic stimulation to the understanding of functional recovery mechanisms after stroke. Neurorehabil. Neural Repair. 2010; 24:125-135. [PubMed: 19767591]

8. Floel A, Cohen LG. Recovery of function in humans: cortical stimulation and pharmacological treatments after stroke. Neurobiol. Dis. 2010; 37:243-251. [PubMed: 19520165]

9. Buonomano DV, Merzenich MM. Cortical plasticity: from synapses to maps. Annu. Rev. Neurosci. 1998; 21:149-186. [PubMed: 9530495]

10. Payne BR, Lomber SG. Reconstructing functional systems after lesions of cerebral cortex. Nat. Rev. Neurosci. 2001; 2:911-919. [PubMed: 11733798]

11. Holloway V, et al. The reorganization of sensorimotor function in children after hemispherectomy. A functional MRI and somatosensory evoked potential study. Brain. 2000; 123:2432-2444. [PubMed: 11099446]

12. Berardi N, Pizzorusso T, Maffei L. Critical periods during sensory development. Curr. Opin. Neurobiol. 2000; 10:138-145. [PubMed: 10679428] 
13. Smirnakis SM, et al. Lack of long-term cortical reorganization after macaque retinal lesions. Nature. 2005; 435:300-307. [PubMed: 15902248]

14. Lindvall O, Kokaia Z. Stem cells for the treatment of neurological disorders. Nature. 2006; 441:1094-1096. [PubMed: 16810245]

15. Delcroix GJ, Schiller PC, Benoit JP, Montero-Menei CN. Adult cell therapy for brain neuronal damages and the role of tissue engineering. Biomaterials. 2010; 31:2105-2120. [PubMed: 20005569]

16. Wolpaw JR, Birbaumer N, McFarland DJ, Pfurtscheller G, Vaughan TM. Brain-computer interfaces for communication and control. Clin. Neurophysiol. 2002; 113:767-791. [PubMed: 12048038]

17. Disability: beyond the medical model. Lancet. 2009; 374:1793. [PubMed: 19944842]

18. Bradt J, Magee WL, Dileo C, Wheeler BL, McGilloway E. Music therapy for acquired brain injury. Cochrane Database of Systematic Reviews. 2010 Issue 7. Art. No.: CD006787. doi: 10.1002/14651858.CD006787.pub2.

19. Latimer CP, Keeling J, Lin B, Henderson M, Hale LA. The impact of bilateral therapy on upper limb function after chronic stroke: a systematic review. Disabil. Rehabil. 2010; 32:1221-1231. [PubMed: 20156045]

20. French B, et al. Does repetitive task training improve functional activity after stroke? A Cochrane systematic review and meta-analysis. J. Rehabil. Med. 2010; 42:9-14. [PubMed: 20111838]

21. Khaja AM. Acute ischemic stroke management: administration of thrombolytics, neuroprotectants, and general principles of medical management. Neurol. Clin. 2008; 26:943-961. [PubMed: 19026898]

22. Romero JR, Babikian v. L. Katz DI, Finklestein SP. Neuroprotection and stroke rehabilitation: modulation and enhancement of recovery. Behav. Neurol. 2006; 17:17-24. [PubMed: 16720957]

23. Hurdowar A, et al. Quality of stroke rehabilitation clinical practice guidelines. J. Eval. Clin. Pract. 2007; 13:657-664. [PubMed: 17683311]

24. Quinn TJ, et al. Evidence-based stroke rehabilitation: an expanded guidance document from the european stroke organisation (ESO) guidelines for management of ischaemic stroke and transient ischaemic attack 2008. J. Rehabil. Med. 2009; 41:99-111. [PubMed: 19225703]

25. Bates B, et al. veterans Affairs/Department of Defense Clinical Practice Guideline for the Management of Adult Stroke Rehabilitation Care: executive summary. Stroke. 2005; 36:20492056. [PubMed: 16120847]

26. Dobkin BH. Confounders in rehabilitation trials of task-oriented training: lessons from the designs of the EXCITE and SCILT multicenter trials. Neurorehabil. Neural Repair. 2007; 21:3-13. [PubMed: 17172549]

27. Sirtori V, Corbetta D, Moja L, Gatti R. Constraint-induced movement therapy for upper extremities in stroke patients. Cochrane Database Systematic Reviews. 2009 Issue 4. Art. No.: CD004433. doi:10.1002/14651858.CD004433.pub2.

28. Hakkennes S, Keating JL. Constraint-induced movement therapy following stroke: a systematic review of randomised controlled trials. Aust. J. Physiother. 2005; 51:221-231. [PubMed: 16321129]

29. Liepert J. Evidence-based therapies for upper extremity dysfunction. Curr. Opin. Neurol. doi: 10.1097/wCO.0b013e32833ff4c4.

30. Hesse S. Treadmill training with partial body weight support after stroke: a review. NeuroRehabilitation. 2008; 23:55-65. [PubMed: 18356589]

31. Moseley AM, Stark A, Cameron ID, Pollock A. Treadmill training and body weight support for walking after stroke. Cochrane Database Systematic Reviews. Issue 4. Art. No.: CD002840. doi: 10.1002/14651858. CD002840.pub2 (2005).

32. Page SJ, Szaflarski JP, Eliassen JC, Pan H, Cramer SC. Cortical plasticity following motor skill learning during mental practice in stroke. Neurorehabil. Neural Repair. 2009; 23:382-388. [PubMed: 19155350]

33. Sharma N, Baron JC, Rowe JB. Motor imagery after stroke: relating outcome to motor network connectivity. Ann. Neurol. 2009; 66:604-616. [PubMed: 19938103] 
34. Coupar F, Pollock A, van wijck F, Morris J, Langhorne P. Simultaneous bilateral training for improving arm function after stroke. Cochrane Database Systematic Reviews. 2010 Issue 4. Art. No.: CD006432. doi:10.1002/14651858. CD006432.pub2.

35. Volpe BT, et al. Robotic devices as therapeutic and diagnostic tools for stroke recovery. Arch. Neurol. 2009; 66:1086-1090. [PubMed: 19752297]

36. Lo AC, et al. Robot-assisted therapy for long-term upper-limb impairment after stroke. N. Engl. J. Med. 2010; 362:1772-1783. [PubMed: 20400552]

37. Kwakkel G, Kollen BJ, Krebs HI. Effects of robot-assisted therapy on upper limb recovery after stroke: a systematic review. Neurorehabil. Neural Repair. 2008; 22:111-121. [PubMed: 17876068]

38. Henderson A, Korner-Bitensky N, Levin M. virtual reality in stroke rehabilitation: a systematic review of its effectiveness for upper limb motor recovery. Top. Stroke Rehabil. 2007; 14:52-61. [PubMed: 17517575]

39. Zimmermann-Schlatter A, Schuster C, Puhan MA, Siekierka E, Steurer J. Efficacy of motor imagery in post-stroke rehabilitation: a systematic review. J. Neuroeng. Rehabil. 2008; 5:8. [PubMed: 18341687]

40. Dromerick AW, et al. very early constraint-induced movement during stroke rehabilitation (VECTORS): a single-center RCT. Neurology. 2009; 73:195-201. [PubMed: 19458319]

41. Wolf SL, et al. Effect of constraint-induced movement therapy on upper extremity function 3 to 9 months after stroke: the EXCITE randomized clinical trial. JAMA. 2006; 296:2095-2104. [PubMed: 17077374]

42. Greener J, Langhorne P. Systematic reviews in rehabilitation for stroke: issues and approaches to addressing them. Clin. Rehabil. 2002; 16:69-74. [PubMed: 11837528]

43. Brown CE, Aminoltejari K, Erb H, winship IR, Murphy TH. In vivo voltage-sensitive dye imaging in adult mice reveals that somatosensory maps lost to stroke are replaced over weeks by new structural and functional circuits with prolonged modes of activation within both the peri-infarct zone and distant sites. J. Neurosci. 2009; 29:1719-1734. [PubMed: 19211879]

44. Jones TA, Kleim JA, Greenough WT. Synaptogenesis and dendritic growth in the cortex opposite unilateral sensorimotor cortex damage in adult rats: a quantitative electron microscopic examination. Brain Res. 1996; 733:142-148. [PubMed: 8891261]

45. Dancause N, et al. Extensive cortical rewiring after brain injury. J. Neurosci. 2005; 25:1016710179. [PubMed: 16267224]

46. Weidner N, Ner A, Salimi N, Tuszynski MH. Spontaneous corticospinal axonal plasticity and functional recovery after adult central nervous system injury. Proc. Natl Acad. Sci. USA. 2001; 98:3513-3518. [PubMed: 11248109]

47. Carmichael ST. Cellular and molecular mechanisms of neural repair after stroke: making waves. Ann. Neurol. 2006; 59:735-742. [PubMed: 16634041]

48. Greenough WT, Larson JR, Withers GS. Effects of unilateral and bilateral training in a reaching task on dendritic branching of neurons in the rat motor-sensory forelimb cortex. Behav. Neural Biol. 1985; 44:301-314. [PubMed: 2415103]

49. Jones TA, Chu CJ, Grande LA, Gregory AD. Motor skills training enhances lesion-induced structural plasticity in the motor cortex of adult rats. J. Neurosci. 1999; 19:10153-10163. [PubMed: 10559423]

50. Kleim JA, vij K, Ballard DH, Greenough WT. Learning-dependent synaptic modifications in the cerebellar cortex of the adult rat persist for at least four weeks. J. Neurosci. 1997; 17:717-721. [PubMed: 8987793]

51. Stroemer RP, Kent TA, Hulsebosch CE. Neocortical neural sprouting, synaptogenesis, and behavioral recovery after neocortical infarction in rats. Stroke. 1995; 26:2135-2144. [PubMed: 7482662]

52. Biernaskie J, Corbett D. Enriched rehabilitative training promotes improved forelimb motor function and enhanced dendritic growth after focal ischemic injury. J. Neurosci. 2001; 21:52725280. [PubMed: 11438602]

53. Adkins DL, Boychuk J, Remple MS, Kleim JA. Motor training induces experience- specific patterns of plasticity across motor cortex and spinal cord. J. Appl. Physiol. 2006; 101:1776-1782. [PubMed: 16959909] 
54. Stinear CM, et al. Functional potential in chronic stroke patients depends on corticospinal tract integrity. Brain. 2007; 130:170-180. [PubMed: 17148468]

55. Schaechter JD, Perdue KL, wang R. Structural damage to the corticospinal tract correlates with bilateral sensorimotor cortex reorganization in stroke patients. Neuroimage. 2008; 39:1370-1382. [PubMed: 18024157]

56. Ward NS, Frackowiak RS. The functional anatomy of cerebral reorganisation after focal brain injury. J. Physiol. Paris. 2006; 99:425-436. [PubMed: 16750616]

57. Johansen-Berg H. Functional imaging of stroke recovery: what have we learnt and where do we go from here? Int. J. Stroke. 2007; 2:7-16. [PubMed: 18705982]

58. Krakauer JW. Functional imaging of motor recovery after stroke: remaining challenges. Curr. Neurol. Neurosci. Rep. 2004; 4:42-46. [PubMed: 14683627]

59. Marshall RS, et al. Evolution of cortical activation during recovery from corticospinal tract infarction. Stroke. 2000; 31:656-661. [PubMed: 10700500]

60. Butefisch CM, Netz J, wessling M, Seitz RJ, Homberg V. Remote changes in cortical excitability after stroke. Brain. 2003; 126:470-481. [PubMed: 12538413]

61. Manganotti P, Acler M, Zanette GP, Smania N, Fiaschi A. Motor. cortical disinhibition during early and late recovery after stroke. Neurorehabil. Neural Repair. 2008; 22:396-403. [PubMed: 18326890]

62. Swayne OB, Rothwell JC, Ward NS, Greenwood RJ. Stages of motor output reorganization after hemispheric stroke suggested by longitudinal studies of cortical physiology. Cereb. Cortex. 2008; 18:1909-1922. [PubMed: 18234688]

63. Murase N, Duque J, Mazzocchio R, Cohen LG. Influence of interhemispheric interactions on motor function in chronic stroke. Ann. Neurol. 2004; 55:400-409. [PubMed: 14991818]

64. Cramer SC, et al. Predicting functional gains in a stroke trial. Stroke. 2007; 38:2108-2114. [PubMed: 17540966]

65. Marshall RS, et al. Early imaging correlates of subsequent motor recovery after stroke. Ann. Neurol. 2009; 65:596-602. [PubMed: 19479972]

66. Ward NS, Cohen LG. Mechanisms underlying recovery of motor function after stroke. Arch. Neurol. 2004; 61:1844-1848. [PubMed: 15596603]

67. Ward NS, et al. Motor system activation after subcortical stroke depends on corticospinal system integrity. Brain. 2006; 129:809-819. [PubMed: 16421171]

68. Newton JM, et al. Non-invasive mapping of corticofugal fibres from multiple motor areasrelevance to stroke recovery. Brain. 2006; 129:1844-1858. [PubMed: 16702192]

69. Johansen-Berg H, et al. The role of ipsilateral premotor cortex in hand movement after stroke. Proc. Natl Acad. Sci. USA. 2002; 99:14518-14523. [PubMed: 12376621]

70. Logothetis NK. What we can do and what we cannot do with fMRI. Nature. 2008; 453:869-878. [PubMed: 18548064]

71. Chen R, et al. The clinical diagnostic utility of transcranial magnetic stimulation: report of an IFCN committee. Clin. Neurophysiol. 2008; 119:504-532. [PubMed: 18063409]

72. Baron JC, et al. Neuroimaging in stroke recovery: a position paper from the First International workshop on Neuroimaging and Stroke Recovery. Cerebrovasc. Dis. 2004; 18:260-267. [PubMed: 15484327]

73. Milot MH, Cramer SC. Biomarkers of recovery after stroke. Curr. Opin. Neurol. 2008; 21:654659. [PubMed: 18989108]

74. Cheeran B, et al. The future of restorative neurosciences in stroke: driving the translational research pipeline from basic science to rehabilitation of people after stroke. Neurorehabil. Neural Repair. 2009; 23:97-107. [PubMed: 19189939]

75. Macht MB. Effects of delta-amphetamine on hemi-decorticate, decorticate, and decerebrate cats. Am. J. Physiol. 1950; 163:731-732.

76. Feeney DM, Gonzalez A, Law WA. Amphetamine, haloperidol, and experience interact to affect rate of recovery after motor cortex injury. Science. 1982; 217:855-857. [PubMed: 7100929]

77. Bütefisch CM, et al. Modulation of use-dependent plasticity by d-amphetamine. Ann. Neurol. 2002; 51:59-68. [PubMed: 11782985] 
78. Sawaki L, Cohen LG, Classen J, Davis BC, Bütefisch CM. Enhancement of use-dependent plasticity by D-amphetamine. Neurology. 2002; 59:1262-1264. [PubMed: 12391362]

79. Crisostomo EA, Duncan PW, Propst M, Dawson DV, Davis JN. Evidence that amphetamine with physical therapy promotes recovery of motor function in stroke patients. Ann. Neurol. 1988; 23:94-97. [PubMed: 3345072]

80. Goldstein LB. Amphetamine trials and tribulations. Stroke. 2009; 40:S133-S135. [PubMed: 19064783]

81. Martinsson L, Wahlgren NG, Hardemark HG. Amphetamines for improving recovery after stroke. Cochrane Database Systematic Reviews. 2003 Issue 3. Art. No.: CD002090. doi: 10.1002/14651858.CD002090.

82. Martinsson L, Wahlgren NG. Safety of dexamphetamine in acute ischemic stroke: a randomized, double-blind, controlled dose-escalation trial. Stroke. 2003; 34:475-481. [PubMed: 12574563]

83. Barbay S, Nudo RJ. The effects of amphetamine on recovery of function in animal models of cerebral injury: a critical appraisal. NeuroRehabilitation. 2009; 25:5-17. [PubMed: 19713615]

84. Scheidtmann K, Fries W, Muller F, Koenig E. Effect of levodopa in combination with physiotherapy on functional motor recovery after stroke: a prospective, randomised, double-blind study. Lancet. 2001; 358:787-790. [PubMed: 11564483]

85. Sonde L, Lokk J. Effects of amphetamine and/or L-dopa and physiotherapy after stroke-a blinded randomized study. Acta Neurol. Scand. 2007; 115:55-59. [PubMed: 17156266]

86. Saver JL. Citicoline: update on a promising and widely available agent for neuroprotection and neurorepair. Rev. Neurol. Dis. 2008; 5:167-177. [PubMed: 19122569]

87. Whyte EM, et al. An open-label pilot study of acetylcholinesterase inhibitors to promote functional recovery in elderly cognitively impaired stroke patients. Cerebrovasc. Dis. 2008; 26:317-321. [PubMed: 18667813]

88. Zorowitz RD. Road to recovery: drugs used in stroke rehabilitation. Expert Rev. Neurother. 2004; 4:219-231. [PubMed: 15853563]

89. Nadeau SE, et al. Donepezil as an adjuvant to constraint-induced therapy for upper-limb dysfunction after stroke: an exploratory randomized clinical trial. J. Rehabil. Res. Dev. 2004; 41:525-534. [PubMed: 15558381]

90. Berends HI, et al. The clinical use of drugs influencing neurotransmitters in the brain to promote motor recovery after stroke; a Cochrane systematic review. Eur. J. Phys. Rehabil. Med. 2009; 45:621-630. [PubMed: 20032921]

91. Cohen S, Levi-Montalcini R, Hamburger V. A nerve growth-stimulating factor isolated from sarcom as 37 and 180. Proc. Natl Acad. Sci. USA. 1954; 40:1014-1018. [PubMed: 16589582]

92. Altman J. Are new neurons formed in the brains of adult mammals? Science. 1962; 135:11271128. [PubMed: 13860748]

93. Finklestein SP, et al. Growth factor expression after stroke. Stroke. 1990; 21(Suppl. 11):122-124.

94. Carmichael ST. Gene expression changes after focal stroke, traumatic brain and spinal cord injuries. Curr. Opin. Neurol. 2003; 16:699-704. [PubMed: 14624079]

95. Case LC, Tessier-Lavigne M. Regeneration of the adult central nervous system. Curr. Biol. 2005; 15:R749-R753. [PubMed: 16169471]

96. Li Q, Brus-Ramer M, Martin JH, McDonald JW. Electrical stimulation of the medullary pyramid promotes proliferation and differentiation of oligodendrocyte progenitor cells in the corticospinal tract of the adult rat. Neurosci. Lett. 2010; 479:128-133. [PubMed: 20493923]

97. Benowitz LI, Carmichael ST. Promoting axonal rewiring to improve outcome after stroke. Neurobiol. Dis. 2010; 37:259-266. [PubMed: 19931616]

98. Popa-Wagner A, et al. Effects of granulocyte-colony stimulating factor after stroke in aged rats. Stroke. 2010; 41:1027-1031. [PubMed: 20360546]

99. Shyu WC, et al. Functional recovery of stroke rats induced by granulocyte colony-stimulating factor-stimulated stem cells. Circulation. 2004; 110:1847-1854. [PubMed: 15381647]

100. Minnerup J, et al. Meta-analysis of the efficacy of granulocyte-colony stimulating factor in animal models of focal cerebral ischemia. Stroke. 2008; 39:1855-1861. [PubMed: 18403735] 
101. Shingo T, Sorokan ST, Shimazaki T, Weiss S. Erythropoietin regulates the in vitro and in vivo production of neuronal progenitors by mammalian forebrain neural stem cells. J. Neurosci. 2001; 21:9733-9743. [PubMed: 11739582]

102. Belayev L, et al. A novel neurotrophic therapeutic strategy for experimental stroke. Brain Res. 2009; 1280:117-123. [PubMed: 19463796]

103. Kolb B, et al. Growth factor-stimulated generation of new cortical tissue and functional recovery after stroke damage to the motor cortex of rats. J. Cereb. Blood Flow Metab. 2007; 27:983-997. [PubMed: 16985505]

104. Schabitz WR, et al. Effect of brain-derived neurotrophic factor treatment and forced arm use on functional motor recovery after small cortical ischemia. Stroke. 2004; 35:992-997. [PubMed: 14988579]

105. Ploughman M, et al. Brain-derived neurotrophic factor contributes to recovery of skilled reaching after focal ischemia in rats. Stroke. 2009; 40:1490-1495. [PubMed: 19164786]

106. Muller HD, et al. Brain-derived neurotrophic factor but not forced arm use improves long-term outcome after photothrombotic stroke and transiently upregulates binding densities of excitatory glutamate receptors in the rat brain. Stroke. 2008; 39:1012-1021. [PubMed: 18239176]

107. Ehrenreich H, et al. Recombinant human erythropoietin in the treatment of acute ischemic stroke. Stroke. 2009; 40:e647-e656. [PubMed: 19834012]

108. Cramer SC, et al. The beta-hCG+erythropoietin in acute stroke (BETAS) study: a 3-center, singledose, open-label, noncontrolled, phase IIa safety trial. Stroke. 2010; 41:927-931. [PubMed: 20203320]

109. Floel A, Hummel F, Duque J, Knecht S, Cohen LG. Influence of somatosensory input on interhemispheric interactions in patients with chronic stroke. Neurorehabil. Neural Repair. 2008; 22:477-485. [PubMed: 18645188]

110. Conforto AB, Kaelin-Lang A, Cohen LG. Increase in hand muscle strength of stroke patients after somatosensory stimulation. Ann. Neurol. 2002; 51:122-125. [PubMed: 11782992]

111. Conforto $\mathrm{AB}$, et al. Effects of somatosensory stimulation on motor function after subacute stroke. Neurorehabil. Neural Repair. 2010; 24:263-272. [PubMed: 19884642]

112. Ridding MC, Rothwell JC. Afferent input and cortical organisation: a study with magnetic stimulation. Exp. Brain Res. 1999; 126:536-544. [PubMed: 10422717]

113. Spiegel J, Tintera J, Gawehn J, Stoeter P, Treede RD. Functional MRI of human primary somatosensory and motor cortex during median nerve stimulation. Clin. Neurophysiol. 1999; 110:47-52. [PubMed: 10348320]

114. Han BS, et al. Functional magnetic resonance image finding of cortical activation by neuromuscular electrical stimulation on wrist extensor muscles. Am. J. Phys. Med. Rehabil. 2003; 82:17-20. [PubMed: 12510180]

115. Floel A, et al. Influence of somatosensory input on motor function in patients with chronic stroke. Ann. Neurol. 2004; 56:206-212. [PubMed: 15293272]

116. Chae J, Sheffler L, Knutson J. Neuromuscular electrical stimulation for motor restoration in hemiplegia. Top. Stroke Rehabil. 2008; 15:412-426. [PubMed: 19008202]

117. Embrey DG, Holtz SL, Alon G, Brandsma BA, McCoy SW. Functional electrical stimulation to dorsiflexors and plantar flexors during gait to improve walking in adults with chronic hemiplegia. Arch. Phys. Med. Rehabil. 2010; 91:687-696. [PubMed: 20434604]

118. Nowak DA, Grefkes C, Ameli M, Fink GR. Interhemispheric competition after stroke: brain stimulation to enhance recovery of function of the affected hand. Neurorehabil. Neural Repair. 2009; 23:641-656. [PubMed: 19531606]

119. Hesse $\mathrm{S}$, et al. Combined transcranial direct current stimulation and robot-assisted arm training in subacute stroke patients: a pilot study. Restor. Neurol. Neurosci. 2007; 25:9-15. [PubMed: 17473391]

120. Khedr EM, Ahmed MA, Fathy N, Rothwell JC. Therapeutic trial of repetitive transcranial magnetic stimulation after acute ischemic stroke. Neurology. 2005; 65:466-468. [PubMed: 16087918] 
121. Kim YH, et al. Repetitive transcranial magnetic stimulation-induced corticomotor excitability and associated motor skill acquisition in chronic stroke. Stroke. 2006; 37:1471-1476. [PubMed: 16675743]

122. Talelli P, Greenwood RJ, Rothwell JC. Exploring theta burst stimulation as an intervention to improve motor recovery in chronic stroke. Clin. Neurophysiol. 2007; 118:333-342. [PubMed: 17166765]

123. Malcolm MP, et al. Repetitive transcranial magnetic stimulation as an adjunct to constraintinduced therapy: an exploratory randomized controlled trial. Am. J. Phys. Med. Rehabil. 2007; 86:707-715. [PubMed: 17709994]

124. Yozbatiran N, et al. Safety and behavioral effects of high-frequency repetitive transcranial magnetic stimulation in stroke. Stroke. 2009; 40:309-312. [PubMed: 18845801]

125. Hummel F, et al. Effects of non-invasive cortical stimulation on skilled motor function in chronic stroke. Brain. 2005; 128:490-499. [PubMed: 15634731]

126. Hummel FC, et al. Effects of brain polarization on reaction times and pinch force in chronic stroke. BMC Neurosci. 2006; 7:73. [PubMed: 17083730]

127. Hummel F, Cohen LG. Improvement of motor function with noninvasive cortical stimulation in a patient with chronic stroke. Neurorehabil. Neural Repair. 2005; 19:14-19. [PubMed: 15673839]

128. Boggio PS, et al. Repeated sessions of noninvasive brain DC stimulation is associated with motor function improvement in stroke patients. Restor. Neurol. Neurosci. 2007; 25:123-129. [PubMed: 17726271]

129. Koganemaru S, et al. Recovery of upper-limb function due to enhanced use-dependent plasticity in chronic stroke patients. Brain. 2010; 133:3373-3384. [PubMed: 20688810]

130. Ameli M, et al. Differential effects of high-frequency repetitive transcranial magnetic stimulation over ipsilesional primary motor cortex in cortical and subcortical middle cerebral artery stroke. Ann. Neurol. 2009; 66:298-309. [PubMed: 19798637]

131. Brown JA, Lutsep H, Cramer SC, Weinand M. Motor cortex stimulation for enhancement of recovery after stroke: case report. Neurol. Res. 2003; 25:815-818. [PubMed: 14669524]

132. Brown JA, Lutsep HL, Weinand M, Cramer SC. Motor cortex stimulation for the enhancement of recovery from stroke: a prospective, multicenter safety study. Neurosurgery. 2006; 58:464-473. [PubMed: 16528186]

133. Levy R, et al. Cortical stimulation for the rehabilitation of patients with hemiparetic stroke: a multicenter feasibility study of safety and efficacy. J. Neurosurg. 2008; 108:707-714. [PubMed: 18377250]

134. Neuroregeneration enhanced by transcranial direct current current stimulation (TDCS) in stroke NCT00909714. US NIH ClinicalTrials.gov. 2010 [online], http://clinicaltrials.gov/ct2/results? term=NCT00909714.

135. Fritsch B, et al. Direct current stimulation promotes BDNF-dependent synaptic plasticity: potential implications for motor learning. Neuron. 2010; 66:198-204. [PubMed: 20434997]

136. Liebetanz D, Nitsche MA, Tergau F, Paulus W. Pharmacological approach to the mechanisms of transcranial DC-stimulation-induced after-effects of human motor cortex excitability. Brain. 2002; 125:2238-2247. [PubMed: 12244081]

137. Strafella AP, Paus T, Fraraccio M, Dagher A. Striatal dopamine release induced by repetitive transcranial magnetic stimulation of the human motor cortex. Brain. 2003; 126:2609-2615. [PubMed: 12937078]

138. Nitsche MA, et al. GABAergic modulation of DC stimulation-induced motor cortex excitability shifts in humans. Eur. J. Neurosci. 2004; 19:2720-2726. [PubMed: 15147306]

139. Siebner HR, Rothwell J. Transcranial magnetic stimulation: new insights into representational cortical plasticity. Exp. Brain Res. 2003; 148:1-16. [PubMed: 12478392]

140. Ward NS, Brown MM, Thompson AJ, Frackowiak RS. Neural correlates of motor recovery after stroke: a longitudinal fMRI study. Brain. 2003; 126:2476-2496. [PubMed: 12937084]

141. Lotze $\mathrm{M}$, et al. The role of multiple contralesional motor areas for complex hand movements after internal capsular lesion. J. Neurosci. 2006; 26:6096-6102. [PubMed: 16738254] 
142. Gerloff C, et al. Multimodal imaging of brain reorganization in motor areas of the contralesional hemisphere of well recovered patients after capsular stroke. Brain. 2006; 129:791-808. [PubMed: $16364955]$

143. Nair DG, et al. Imaging correlates of motor recovery from cerebral infarction and their physiological significance in well-recovered patients. Neuroimage. 2007; 34:253-263. [PubMed: 17070707]

144. Duque J, et al. Transcallosal inhibition in chronic subcortical stroke. Neuroimage. 2005; 28:940946. [PubMed: 16084737]

145. Kinsbourne M. Hemi-neglect and hemisphere rivalry. Adv. Neurol. 1977; 18:41-49. [PubMed: 920524]

146. Takeuchi N, Chuma T, Matsuo Y, Watanabe I, Ikoma K. Repetitive transcranial magnetic stimulation of contralesional primary motor cortex improves hand function after stroke. Stroke. 2005; 36:2681-2686. [PubMed: 16254224]

147. Mansur CG, et al. A sham stimulation-controlled trial of rTMS of the unaffected hemisphere in stroke patients. Neurology. 2005; 64:1802-1804. [PubMed: 15911819]

148. Fregni F, et al. A sham-controlled trial of a 5-day course of repetitive transcranial magnetic stimulation of the unaffected hemisphere in stroke patients. Stroke. 2006; 37:2115-2122. [PubMed: 16809569]

149. Nowak DA, et al. Effects of low-frequency repetitive transcranial magnetic stimulation of the contralesional primary motor cortex on movement kinematics and neural activity in subcortical stroke. Arch. Neurol. 2008; 65:741-747. [PubMed: 18541794]

150. Kirton A, et al. Contralesional repetitive transcranial magnetic stimulation for chronic hemiparesis in subcortical paediatric stroke: a randomised trial. Lancet Neurol. 2008; 7:507-513. [PubMed: 18455961]

151. Liepert J, Zittel S, Weiller C. Improvement of dexterity by single session low-frequency repetitive transcranial magnetic stimulation over the contralesional motor cortex in acute stroke: a doubleblind placebo-controlled crossover trial. Restor. Neurol. Neurosci. 2007; 25:461-465. [PubMed: 18334764]

152. Takeuchi $\mathrm{N}$, et al. Inhibition of the unaffected motor cortex by $1 \mathrm{~Hz}$ repetitive transcranical magnetic stimulation enhances motor performance and training effect of the paretic hand in patients with chronic stroke. J. Rehabil. Med. 2008; 40:298-303. [PubMed: 18382826]

153. Ackerley SJ, Stinear CM, Barber PA, Byblow WD. Combining theta burst stimulation with training after subcortical stroke. Stroke. 2010; 41:1568-1572. [PubMed: 20489170]

154. Celnik P, Paik NJ, Vandermeeren Y, Dimyan M, Cohen LG. Effects of combined peripheral nerve stimulation and brain polarization on performance of a motor sequence task after chronic stroke. Stroke. 2009; 40:1764-1771. [PubMed: 19286579]

155. Shin HI, Han TR, Paik NJ. Effect of consecutive application of paired associative stimulation on motor recovery in a rat stroke model: a preliminary study. Int. J. Neurosci. 2008; 118:807-820. [PubMed: 18465426]

156. Castel-Lacanal E, et al. Induction of cortical plastic changes in wrist muscles by paired associative stimulation in the recovery phase of stroke patients. Neurorehabil. Neural Repair. 2009; 23:366-372. [PubMed: 19060132]

157. Castel-Lacanal E, Gerdelat-Mas A, Marque P, Loubinoux I, Simonetta-Moreau M. Induction of cortical plastic changes in wrist muscles by paired associative stimulation in healthy subjects and post-stroke patients. Exp. Brain Res. 2007; 180:113-122. [PubMed: 17265041]

158. Jayaram G, Stinear JW. Contralesional paired associative stimulation increases paretic lower limb motor excitability post-stroke. Exp. Brain Res. 2008; 185:563-570. [PubMed: 17973101]

159. Grefkes C, et al. Modulating cortical connectivity in stroke patients by rTMS assessed with fMRI and dynamic causal modeling. Neuroimage. 2010; 50:233-242. [PubMed: 20005962]

160. Perez MA, Cohen LG. Mechanisms underlying functional changes in the primary motor cortex ipsilateral to an active hand. J. Neurosci. 2008; 28:5631-5640. [PubMed: 18509024]

161. Lindvall O, Kokaia Z. Stem cells in human neurodegenerative disorders-time for clinical translation? J. Clin. Invest. 2010; 120:29-40. [PubMed: 20051634] 
162. Pilot investigation of stem cells in stroke (PISCES) NCT01151124. US NIH ClinicalTrials. gov. 2010 [online], http://clinicaltrials.gov/ct2/show/NCT01151124.

163. Jin K, et al. Transplantation of human neural precursor cells in Matrigel scaffolding improves outcome from focal cerebral ischemia after delayed postischemic treatment in rats. J. Cereb. Blood Flow Metab. 2010; 30:534-544. [PubMed: 19826433]

164. Zhong J, et al. Hydrogel matrix to support stem cell survival after brain transplantation in stroke. Neurorehabil. Neural Repair. 2010; 24:636-644. [PubMed: 20424193]

165. Kubinova S, Sykova E. Nanotechnology for treatment of stroke and spinal cord injury. Nanomedicine (Lond.). 2010; 5:99-108. [PubMed: 20025468]

166. Daly JJ, Wolpaw JR. Brain-computer interfaces in neurological rehabilitation. Lancet Neurol. 2008; 7:1032-1043. [PubMed: 18835541]

167. Buch E, et al. Think to move: a neuromagnetic brain-computer interface (BCI) system for chronic stroke. Stroke. 2008; 39:910-917. [PubMed: 18258825]

168. Wang W, et al. Neural interface technology for rehabilitation: exploiting and promoting neuroplasticity. Phys. Med. Rehabil. Clin. N. Am. 2010; 21:157-178. [PubMed: 19951784]

169. Daly JJ, et al. Feasibility of a new application of noninvasive brain computer interface (BCI): a case study of training for recovery of volitional motor control after stroke. J. Neurol. Phys. Ther. 2009; 33:203-211. [PubMed: 20208465]

170. Broetz D, et al. Combination of brain-computer interface training and goal-directed physical therapy in chronic stroke: a case report. Neurorehabil. Neural Repair. 2010; 24:674-679. [PubMed: 20519741]

171. Miesenbock G. The optogenetic catechism. Science. 2009; 326:395-399. [PubMed: 19833960]

172. Gradinaru V, et al. Molecular and cellular approaches for diversifying and extending optogenetics. Cell. 2010; 141:154-165. [PubMed: 20303157]

173. Tufail Y, et al. Transcranial pulsed ultrasound stimulates intact brain circuits. Neuron. 2010; 66:681-694. [PubMed: 20547127]

174. Kleim JA, et al. BDNF val66met polymorphism is associated with modified experiencedependent plasticity in human motor cortex. Nat. Neurosci. 2006; 9:735-737. [PubMed: 16680163]

175. Cheeran BJ, Ritter C, Rothwell JC, Siebner HR. Mapping genetic influences on the corticospinal motor system in humans. Neuroscience. 2009; 164:156-163. [PubMed: 19409217]

176. Dahl TH. International classification of functioning, disability and health: an introduction and discussion of its potential impact on rehabilitation services and research. J. Rehabil. Med. 2002; 34:201-204. [PubMed: 12392233]

177. Bendz M. The first year of rehabilitation after a stroke-from two perspectives. Scand. J. Caring Sci. 2003; 17:215-222. [PubMed: 12919455]

178. Page SJ, Levine P, Sisto S, Bond Q, Johnston MV. Stroke patients' and therapists' opinions of constraint-induced movement therapy. Clin. Rehabil. 2002; 16:55-60. [PubMed: 11837526]

179. Patel MD, et al. Relationships between long-term stroke disability, handicap and health-related quality of life. Age Ageing. 2006; 35:273-279. [PubMed: 16638767]

180. Williams LS, Weinberger M, Harris LE, Biller J. Measuring quality of life in a way that is meaningful to stroke patients. Neurology. 1999; 53:1839-1843. [PubMed: 10563636]

181. Levin MF, Kleim JA, Wolf SL. What do motor "recovery" and "compensation" mean in patients following stroke? Neurorehabil. Neural Repair. 2009; 23:313-319. [PubMed: 19118128]

182. Vilkki J, et al. Relationship of the Met allele of the brain-derived neurotrophic factor val66Met polymorphism to memory after aneurysmal subarachnoid hemorrhage. Neurosurgery. 2008; 63:198-203. [PubMed: 18797348]

183. Kim JM, et al. BDNF genotype potentially modifying the association between incident stroke and depression. Neurobiol. Aging. 2008; 29:789-792. [PubMed: 17222482] 


\section{Key points}

Training-based techniques, involving both physical and occupational therapy, continue to be the gold standard for poststroke motor rehabilitation

A better understanding of basic mechanisms of motor function and the pathophysiology of poststroke paresis will guide advances in neural repair and rehabilitation

Pharmacological, biological and electrophysiological techniques are being developed to augment neuroplasticity-induced and training-induced functional gains in patients with stroke

Exogenous cellular and neuroprosthetic technologies could enhance neural repair or offer alternative methods of motor control in patients with stroke

Combining measures of body function, activity, participation and patient quality of life will contribute to comprehensive goal setting in stroke rehabilitation 


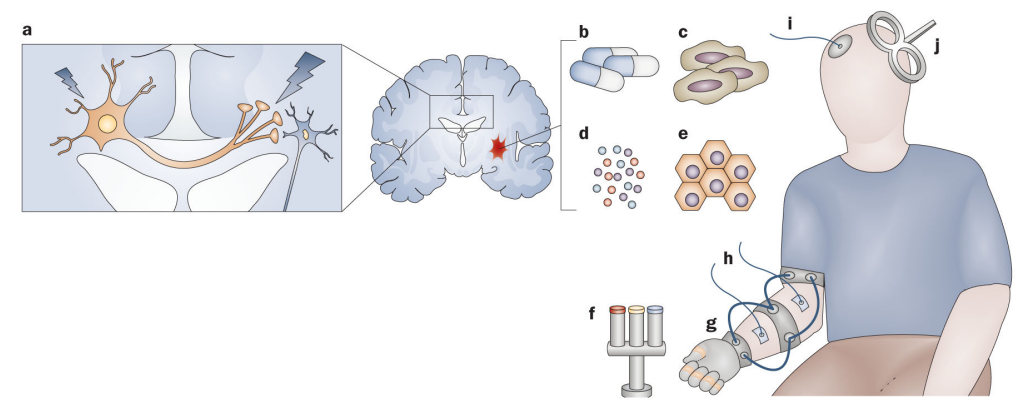

Figure 1.

Treatments currently being explored to enhance poststroke motor rehabilitation. a | Schematic demonstrating the concept of interhemispheric competition in its simplest form, see Dimyan \& Cohen $(2010)^{7}$ for a more detailed model. The large neuron represents the increased interhemispheric inhibition from contralesional to ipsilesional primary motor cortices. The small neuron represents the inhibited ipsilesional corticospinal tract. Invasive and noninvasive stimulation might inhibit activity in the contralesional primary motor cortex and facilitate activity in the ipsilesional primary motor cortex. Other methods that might enhance activity in the ipsilesional corticospinal tract or its related networks (even when delivered systemically) include $\mathbf{b} \mid$ pharmacological interventions targeting neurotransmitter systems, $\mathbf{c} \mid$ stem cells, $\mathbf{d} \mid$ neural growth factors and cytokines and $\mathbf{e} \mid$ exogenous biomaterials. Other experimental interventions that might alleviate poststroke motor impairments include $\mathbf{f} \mid$ robot-assisted training-based therapy, $\mathbf{g} \mid$ use of orthotics to allow neuroprosthetic control or to augment training-based therapies, $\mathbf{h} \mid$ stimulation of peripheral nerves or muscles via surface electrodes, $\mathbf{i}$ | transcranial direct current stimulation, and $\mathbf{j}$ | transcranial magnetic stimulation via a figure-of-eight coil to alter neurophysiological activity in the cortex. 

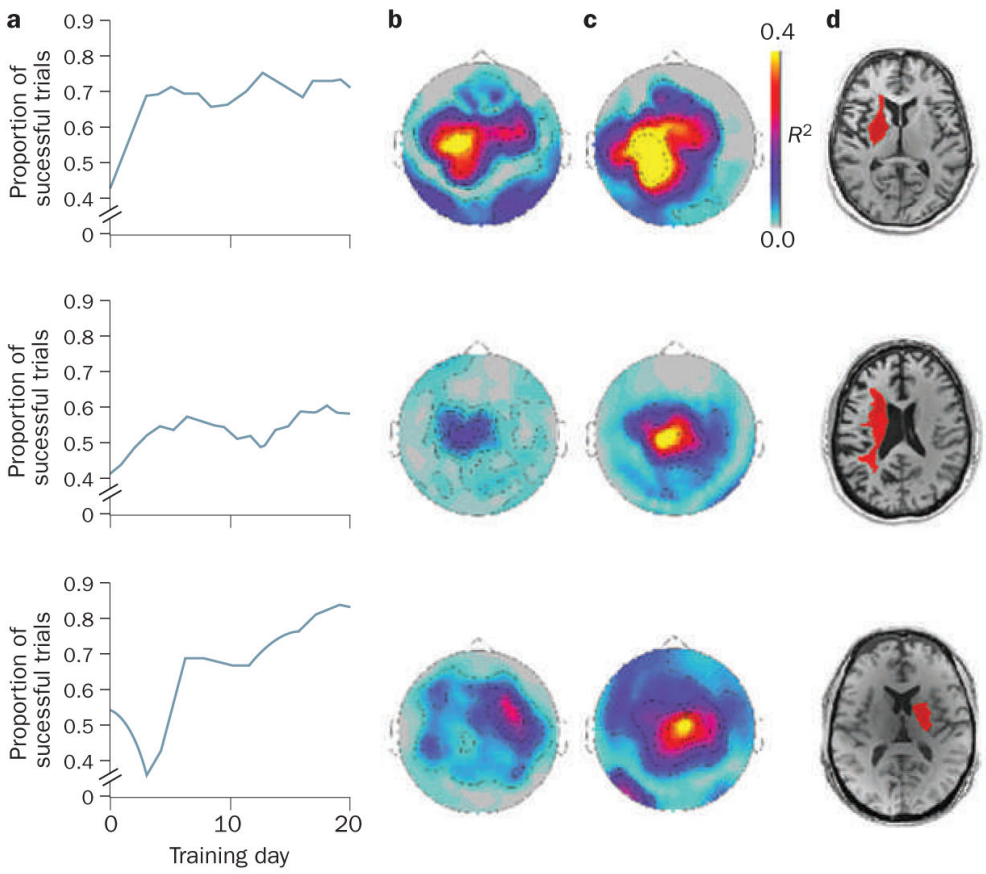

Figure 2.

Brain-computer interface training modulates cortical activity. Patients with chronic hand hemiplegia after stroke were trained to move a cursor on a screen via modulation of ipsilesional sensorimotor $\mu$ rhythm, which was recorded by magnetoencephalography. Successful trials led to the brain-computer interface opening or closing the patient's paralyzed hand via a mechanized orthosis. This figure shows the results from three patients. a The performance of these patients across sessions indicates that the proportion of successful trials increased over time. The statistical maps for the correlations between sensorimotor $\mu$ rhythm amplitude, which was recorded from sensors above the ipsilesional primary motor cortex, and successful performance at $\mathbf{b} \mid$ early or $\mathbf{c} \mid$ late training time points demonstrate modulation of sensorimotor rhythm with brain-computer interface training. Red and yellow colors identify areas where there was a high degree of correlation. $\mathbf{d} \mid$ Single axial images from T1-weighted, high-resolution MRI scans obtained for each patient. Each patient's lesion is highlighted in red. Adapted from (C) Buch et al. Stroke 39, 910-917 (2008). 